\title{
Delayed Diagnosis of Rheumatic Heart Disease
}

Deepa Bhanot, MD, Jill Hanrahan, MD, Wassim Shaheen, MD

\section{Introduction}

Non-suppurative cardiovascular sequelae of group A streptococcal pharyngitis remain medical and public health problems worldwide, though more rampant in the developing world. The mean incidence is 19 cases per 100,000 persons in the developing world and 2 to 14 cases per 100,000 persons in the United States.

\section{Case Presentation}

A 32-year-old female presented to the ED complaining of shortness of air. CT of the chest showed bibasilar interstitial lung infiltrates and pulmonary congestion. She was sent home. One one week later, she presented with pulmonary edema requiring mechanical ventilation. Two dimensional echocardiography showed severe mitral stenosis and moderate aortic insufficiency, consistent with rheumatic valvular disease. Dual valve replacement was performed 15 days later, with resolution of symptoms.

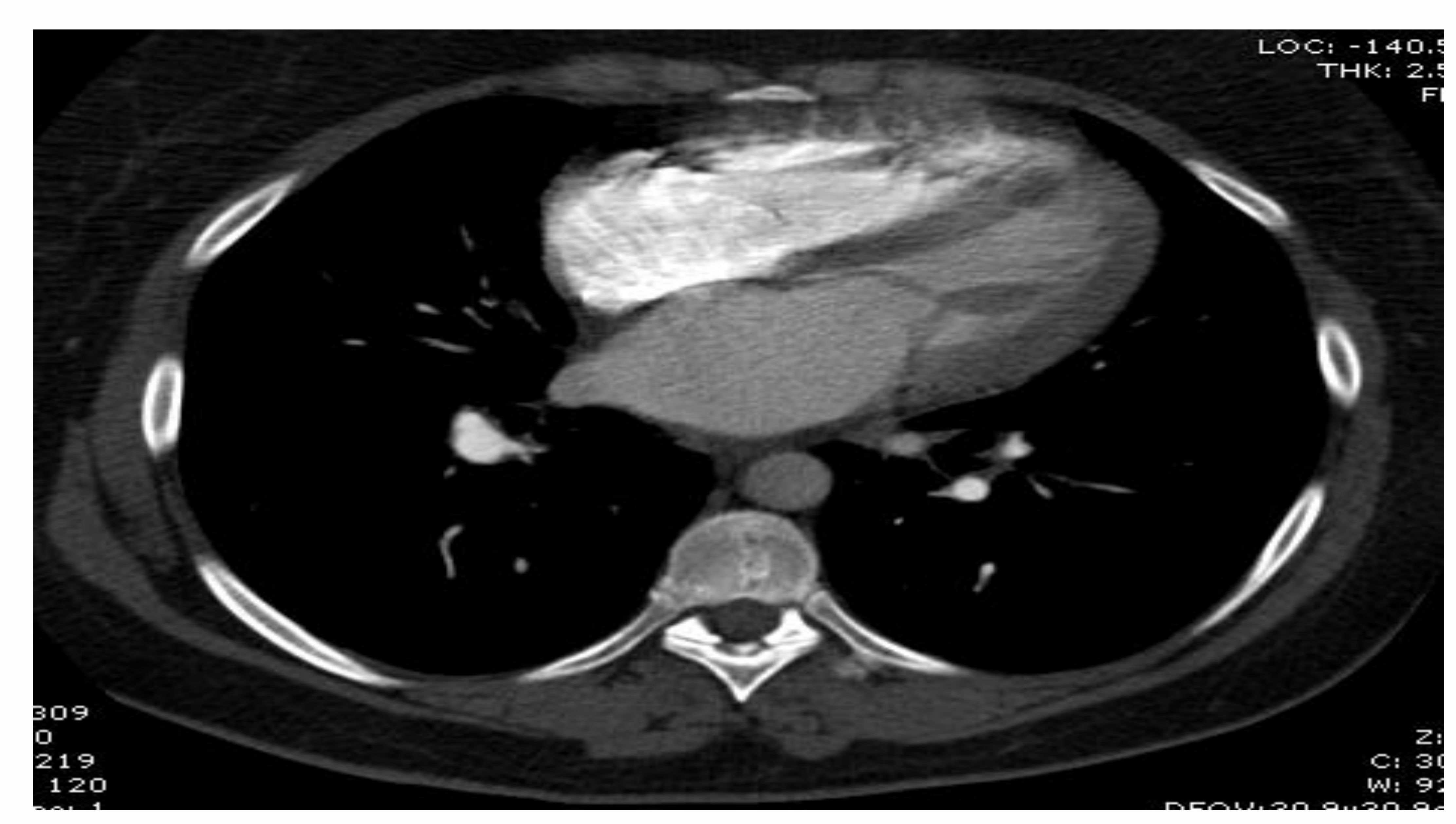

Thick MV and septal bowing

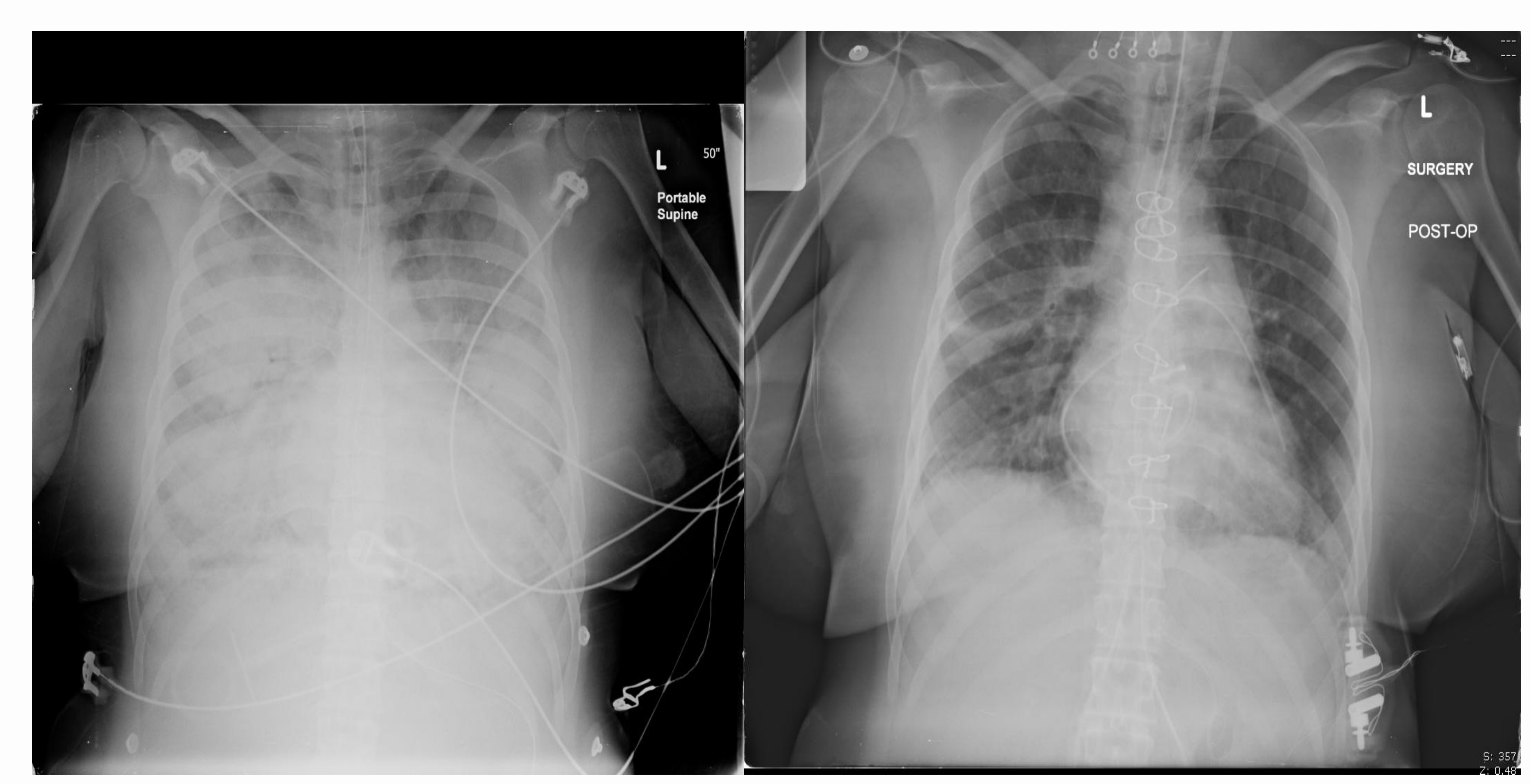

CXR before and after

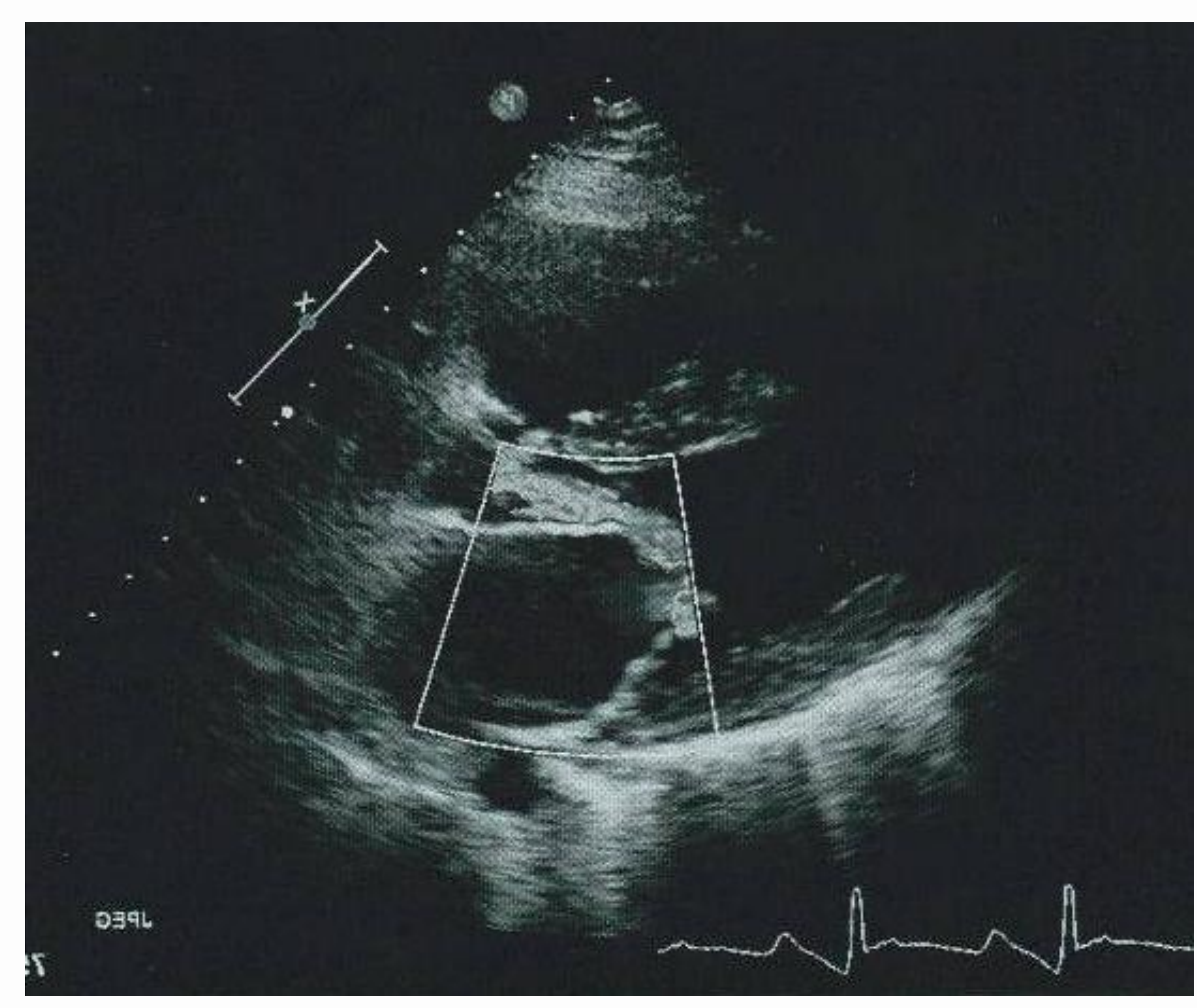

Mitral stenosis and aortic insufficiency

\section{Conclusions}

Diseases forgotten in the developed world should still be present in the differential diagnosis. Failure to recognize them may be fatal.

\section{References}

- Rheumatic fever and rheumatic heart disease -report of a WHO Expert

Consultation. WHO technical report series, 923.

- Kaplan E. Recent epidemiology of Group A streptococcal infections in North America and abroad: an overview. Pediatrics 1996; 97(6): S945-S948.

- Krishna Kumar R, et al. World Health Report. Conquering suffering. Enriching humanity. World Health Organization, 1997:43-44.

- Epidemiology of streptococcal pharyngitis, rheumatic fever and rheumatic heart disease. In: Narula J et al., eds. Rheumatic fever. Washington, DC: American Registry of Pathology Publisher, 1999, 41-78.

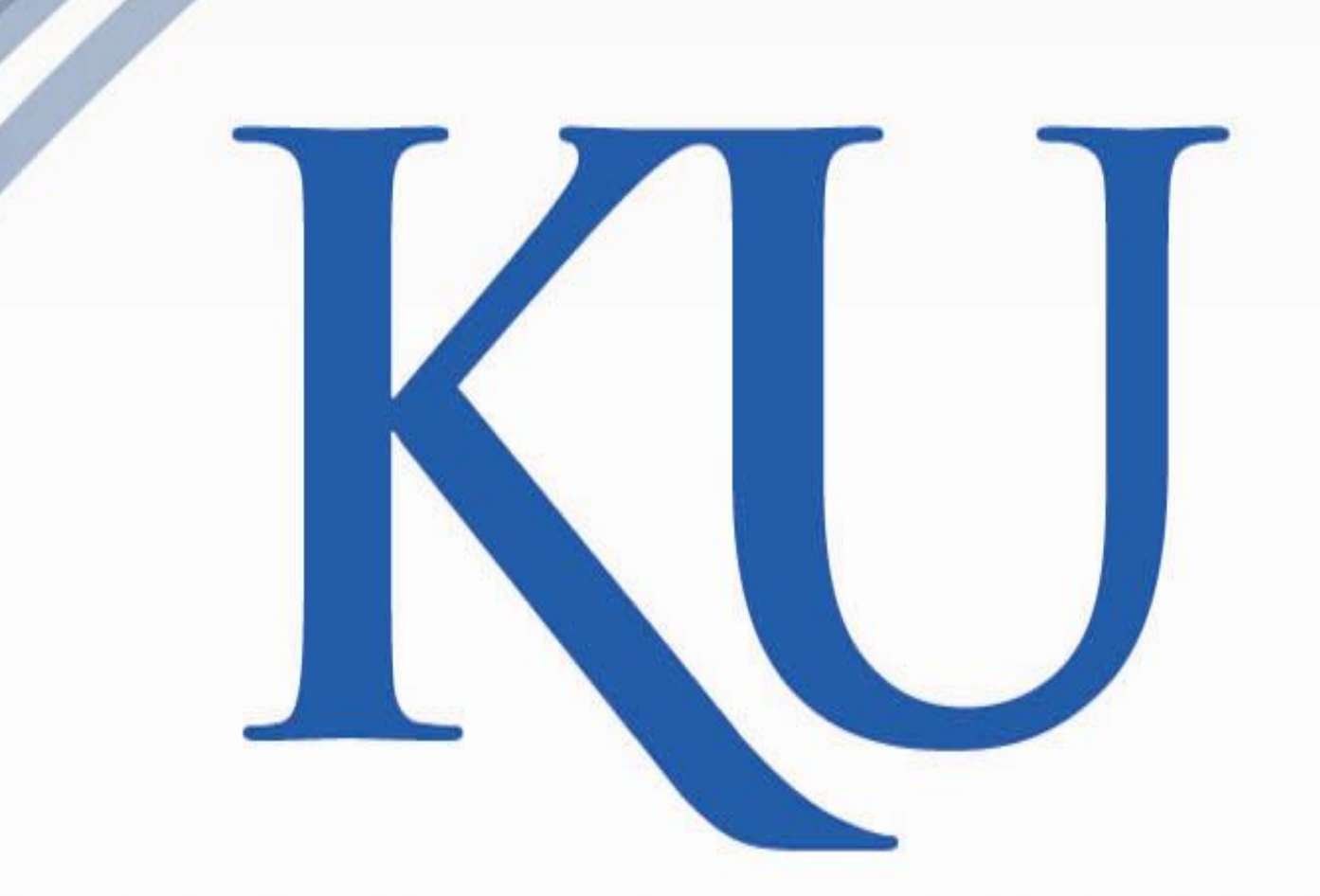

SCHOOL OF MEDICINE WICHITA

The University of Kansas 